\title{
Early detection of acute myocardial infarction: additional diagnostic information from serum concentrations of myoglobin in patients without ST elevation
}

E Magnus Ohman, Catherine Casey, James R Bengtson, David Pryor, William Tormey,
John H Horgan

\begin{abstract}
The value of the 12 lead electrocardiogram, serum total creatine kinase, creatine kinase $M B$ isoenzyme, and myoglobin for the early detection of infarction was evaluated within one hour of admission to the coronary care unit in 82 consecutive patients with suspected myocardial infarction. The 51 patients in whom infarction was diagnosed during the first 24 hours after admission had a higher prevalence of ST elevation $(64 \% v$ $11 \%)$, higher median serum myoglobin $(136 \mu \mathrm{g} / 1 \mathrm{v} 34 \mu \mathrm{g} / 1)$, higher serum creatine kinase (77 IU/1 $v 34$ IU/1), and higher MB isoenzyme ( $7 \mathrm{IU} / 1 v 4 \mathrm{IU} / 1)$ than those in whom it was not. Stepwise logistic regression analysis in 70 patients in whom the electrocardiogram and serum myoglobin were suitable for analysis showed that serum myoglobin was the variable most closely associated with infarction, and contributed additional diagnostic information when ST elevation was entered into the model first. Serum myoglobin remained associated with myocardial infarction when patients who had had symptoms for < six hours were analysed. An algorithm based on a rapid agglutination test for myoglobin and ST elevation on the electrocardiogram gave an accurate diagnosis in $82 \%$ of patients. This approach gave early and rapid recognition of acute myocardial infarction and warrants further examination.
\end{abstract}

Early detection of acute myocardial infarction to identify patients who are suitable for thrombolytic treatment usually includes electrocardiographic changes. ${ }^{1-3}$ ST elevation on the electrocardiogram may, however, be absent in the early phase in up to $40 \%$ of patients. ${ }^{4-7}$ Release of serum markers of myocardial necrosis, such as creatine kinase $\mathrm{MB}$ and myoglobin, may help to identify patients with infarction, ${ }^{8}$ where thrombolytic treatment may reduce mortality. ${ }^{9}$ This study sought to establish which markers of myocardial infarction could be used, in addition to the electrocardiogram, to diagnose correctly most patients.
Patients and methods

PATIENTS

Consecutive patients presenting to an emergency department were seen by a physician on duty who made a clinical diagnosis'of suspected acute myocardial infarction requiring admission to the coronary care unit. Eighty two patients met the following inclusion criteria: $(a)$ cardiac chest pain unrelieved by sublingual glyceryl trinitrate or nifedipine, $(b)$ chest pain lasting $>1$ h but $<24$; $(c)$ age $\leqslant 65$ years. We excluded all patients with shock (systolic blood pressure $<90 \mathrm{~mm} \mathrm{Hg}$ with clinical evidence of hypoperfusion), patients with recent trauma including cardiopulmonary resuscitation, and patients with known severe renal, muscular, or infectious disease. All patients had a 12 lead electrocardiogram recorded and a $10 \mathrm{ml}$ blood sample obtained within one hour of admission to the coronary care unit. A positive diagnosis of myocardial infarction was based on the World Health Organisation criteria. The mean delay from arrival at hospital and admission to the coronary care unit was 108 minutes (range 10-400).

\section{ELECTROCARDIOGRAM ANALYSIS}

The electrocardiogram was read by two independent observers, who were unaware of the clinical details. The observers classified the electrocardiograms into three groups: type 1ST elevation $>1 \mathrm{~mm}$ in a limb lead or $2 \mathrm{~mm}$ in two precordial leads, irrespective of the presence of $Q$ waves; type 2-any electrocardiographic abnormality, including right or left bundle branch block, ST depression, $\mathrm{T}$ wave inversion, or ST elevation less than the criteria for type 1 electrocardiogram; type 3-normal electrocardiogram, including minor $\mathrm{ST}$ and $\mathrm{T}$ wave changes and isolated fascicular blocks. ${ }^{6}$ Each electrocardiogram was assigned to a group according to the most severe abnormality (type $1>$ type $2>$ type 3 ) that was seen.

\section{SERUM ANALYSIS}

Ten millilitres of blood was withdrawn from an antecubital vein. The blood was centrifuged, then serum was taken off and divided into two. The serum was stored at $-20^{\circ} \mathrm{C}$ until assays were performed. Total creatine kinase and its $\mathrm{MB}$ isoenzyme were measured by an enzyme 
immunoinhibition assay kit (BoehringerMannheim Diagnostica). We measured serum myoglobin concentrations in batches of 20 samples by a radioimmunoassay, using a double antibody for myoglobin (NMS Pharmaceuticals, Inc) ${ }^{10}$ and concurrently we also measured serum myoglobin by a rapid latex agglutination test (Boehringer Diagnostica). This test takes 10 minutes to perform and produces a semiquantitative analysis in the range $90-1600 \mu \mathrm{g} / 1 .{ }^{11}$ Data were incomplete in 14 patients because serum samples were not large enough for myoglobin assay, ${ }^{8}$ electrocardiographic tracings were poor ${ }^{4}$ and serum samples were not available for creatine kinase analysis. ${ }^{2}$

\section{DATA ANALYSIS}

We calculated the median and 25th and 75th percentiles for the continuous variables and used the Wilcoxon rank sum test for between group comparisons and Fisher's exact test for analysis of diagnostic groups. The association between continuous variables was analysed by the Spearman rank correlation test. The relative importance and independent contribution of each variable for identifying the correct diagnosis was examined by stepwise logistic regression analysis. Values from serum myoglobin determined by radioimmunoassay were plotted as a cumulative distribution function for patients with and without myocardial infarction. This function gives the probability that the serum myoglobin is less than or equal to a particular value, and can therefore be used to identify a cut off for an abnormal test according to the sensitivity and specificity required. Statistical significance was taken as $\mathrm{p}<0.05$.

\section{Results}

STUDY POPULATION

On follow up 51 patients were diagnosed as having an acute myocardial infarction. The remaining 31 patients were diagnosed as having unstable angina pectoris or non-cardiac chest pain. Table 1 shows the characteristics of the study population. Thirteen patients in the group with myocardial infarction and eight in the group without had chest pain lasting $>6 \mathrm{~h}$.

\section{ELECTROCARDIOGRAMS}

There were 78 electrocardiograms suitable for analysis (table 2). The distribution of electrocardiographic abnormalities (type 1 and

Table 1 Data on study population (medians with interquartile range for continuous variables in parentheses)

\begin{tabular}{lccl}
\hline Variable & $M I(n=51)$ & $\begin{array}{l}\text { Non-MI } \\
(n=31)\end{array}$ & $p$ \\
\hline Male sex & $41(80 \%)$ & $27(87 \%)$ & 0.55 \\
Age (years) & $56(49-60)$ & $55(51-57)$ & $0 \cdot 27$ \\
Chest pain $(\mathrm{h})$ & $4(2-7)$ & $3(2-9)$ & 0.90 \\
Total CK $(\mathrm{IU} / 1)^{\star}$ & $77(11-175)$ & $34(22-47)$ & 0.0001 \\
CK-MB $(\mathrm{IU} / 1)^{\star}$ & $7(3-19)$ & $4(3-6)$ & 0.02 \\
Myoglobin $(\mu \mathrm{g} / \mathrm{l}) \dagger$ & $136(76-335)$ & $34(22-42)$ & 0.0001
\end{tabular}

$\mathrm{CK}$, creatine kinase; $\mathrm{CK}-\mathrm{MB}$, creatine kinase $\mathrm{MB}$ isoenzyme; MI, myocardial infarction.

*Data not available on one patient with myocardial infarction and one without.

tData not available on five patients with myocardial infarction and three without.
Table 2 Classification of admission electrocardiogram

\begin{tabular}{llll}
\hline ECG criteria & $\begin{array}{l}M I \\
n=50(\%)\end{array}$ & $\begin{array}{l}\text { Non-MI } \\
n=28(\%)\end{array}$ & $\begin{array}{l}\text { Total } \\
n=78(\%)\end{array}$ \\
\hline $\begin{array}{l}\text { Type 1 } \\
\text { (ST elevation) }\end{array}$ & $32(64)$ & $3(11)$ & $35(45)$ \\
$\begin{array}{l}\text { Type 2 (abnormal) } \\
\text { Type 3 (normal) }\end{array}$ & $\begin{array}{c}15(30) \\
3(6)\end{array}$ & $\begin{array}{c}21(75) \\
4(14)\end{array}$ & $\begin{array}{c}36(46) \\
7(9)\end{array}$ \\
\hline
\end{tabular}

Electrocardiograms were analysed by two observers who were unaware of the clinical data and classified as described in Methods section. The data are shown as number of patients with each type of electrocardiogram. Electrocardiograms were not suitable for analysis in one patient with myocardial infarction and in three without. See footnote to table 1 for abbreviations.

type 2) differed significantly between the group with myocardial infarction and the group without (Fisher's exact test, $\mathrm{p}<0.001$ ).

CREATINE KINASE AND MB ISOENZYME

Serum concentrations of total creatine kinase and its $\mathrm{MB}$ isoenzyme were measured in 80 patients and both were significantly higher in the group with myocardial infarction during admission than in the group without (table 1). There was a significant positive correlation between the total creatine kinase and its $M B$ isoenzyme in the group with myocardial infarction $(r=0.85 ; p<0.0001)$. In those with myocardial infarction the duration of chest pain was positively correlated with serum concentrations of both total creatine kinase and its $\mathrm{MB}$ isoenzyme $(\mathrm{r}=0.34, \mathrm{p}<0.02 ; \mathrm{r}=0.31$, $\mathrm{p}<0.03$ respectively). No such relation was seen in the group without myocardial infarction (creatine kinase, $r=0.15$; creatine kinase $\mathrm{MB}, \mathrm{r}=0 \cdot 13)$. When patients with chest pain lasting more than six hours were excluded from the analysis, there was no relation between concentrations of creatine kinase or its $\mathrm{MB}$ isoenzyme and the duration of chest pain $(r=0.20$ and $r=0.17$ respectively).

\section{MYOGLOBIN}

Serum myoglobin was measured in 74 patients. The concentration of serum myoglobin was significantly higher in the group with myocardial infarction than in the group without (table 1). There was no appreciable correlation between the duration of symptoms and the serum concentration of myoglobin in either of the groups ( $r=0.18$ in those with myocardial infarction and $r=0.13$ in those without). Serum myoglobin was also analysed by the rapid latex agglutination semiquantiative kit. There was a strong association between the two analyses $\left(\chi^{2}=49.44, \mathrm{p}<0.0001\right)$. The kit was positive (concentration $>90 \mu \mathrm{g} / \mathrm{l}$ ) in $57 \%$ of

Table 3 Semiquantitative analysis of serum myoglobin

\begin{tabular}{lccc}
\hline Kit reading & $\begin{array}{l}M I \\
n=46(\%)\end{array}$ & $\begin{array}{l}\text { Non-MI } \\
n=28(\%)\end{array}$ & $\begin{array}{l}\text { Total } \\
n=74(\%)\end{array}$ \\
\hline $1(<90 \mu \mathrm{g} / \mathrm{l})$ & $20(43)$ & $27(96)$ & $47(64)$ \\
$2(90-200 \mu \mathrm{g} / 1)$ & $9(20)$ & $0(0)$ & $9(12)$ \\
$3(200-400 \mu \mathrm{g} / 1)$ & $16(35)$ & $1(4)$ & $17(23)$ \\
$4(400-1600 \mu \mathrm{g} / \mathrm{l})$ & $1(2)$ & $0(0)$ & $1(1)$ \\
\hline
\end{tabular}

Serum myoglobin was measured by a rapid latex agglutination test. The semiquantitative analysis was obtained by diluting original serum sample serially if the initial reading was positive. Each step was read after five minutes. The data are shown as number of patients in each range. Samples were too small for analysis in five patients with myocardial infarctio and three without. See footnote to table 1 for abbreviations. 
Table 4 Univariate association with myocardial infarction

\begin{tabular}{lll}
\hline Variable & $\begin{array}{l}\text { All patients } \\
(n=68)\end{array}$ & $\begin{array}{l}\text { Chest pain } \\
<6 \text { hours } \\
(n=49)\end{array}$ \\
\hline Myoglobin & 28.66 & 23.74 \\
Myoglobin by kit & 16.95 & 15.11 \\
ECG class 1 & 15.04 & 11.55 \\
ECG class 2 & 9.53 & 5.07 \\
Total CK & 6.31 & 3.09 \\
CK-MB & 4.57 & 1.86 \\
\hline
\end{tabular}

Univariate association with myocardial infarction as measured by logistic regression analysis. The data include only patients in whom all variables were measured. Table entries are $\chi^{2}$
statistics with one degree of freedom. When $\chi^{2}$ is $>3.84, p<$ 0.05 . See footnote to table 1 for abbreviations.
.

patients with myocardial infarction and negative in $96 \%$ of patients without myocardial infarction $(p<0.0001)$. Table 3 shows the results of the semiquantiative analysis of serum myoglobin.

\section{LOGISTIC REGRESSION ANALYSIS}

The variables that might have been associated with myocardial infarction were analysed by stepwise logistic regression analysis in the patients in whom all variables were measuredboth in the total group $(n=68)$ and those with chest pain lasting $<6 \mathrm{~h}(\mathrm{n}=49)$. Table 4 lists these variables. Serum myoglobin was the strongest individual predictor of myocardial infarction $\left(\chi^{2}=33.49 ; \mathrm{p}<0.0001\right)$. After adjusting for the association between presence of ST elevation and myocardial infarction $\left(\chi^{2}=18 \cdot 11\right)$, inclusion of the myoglobin concentration doubled the diagnostic information $\left(\chi^{2}=20.39, p=0.0001\right)$. Similar information was obtained when the myoglobin kit was analysed according to the same model (table 5). In a secondary analysis, the association between the same variables was examined after excluding 21 patients with chest pain lasting $>6 \mathrm{~h}$. The serum concentration of myoglobin remained a good test for the diagnosis of myocardial infarction $\left(\chi^{2}=26 \cdot 34\right.$, $p<0.0001)$. Presence of ST elevation did not yield significant additional information in this model.

\section{Discussion}

Most trials of intravenous thrombolytic agents have used ST elevation on the electrocardiogram as an inclusion criterion. The recently published data from the ISIS-2 trial found a reduced mortality in patients with and without

Table 5 Multivariate contribution of myoglobin and electrocardiogram to diagnosis of myocardial infarction

\begin{tabular}{lcc}
\hline Variable & Alone & $\begin{array}{l}\text { Added } \\
\text { contribution }\end{array}$ \\
\hline ECG (ST elevation) & 18.11 & 5.01 \\
Myoglobin concentration & 33.49 & 20.39 \\
$\begin{array}{l}\text { (radioimmunoassay) } \\
\text { Myoglobin kit }\end{array}$ & 18.11 & 13.52 \\
Myoglon) & 19.60 & 15.01
\end{tabular}

Table entries are $\chi^{2}$ statistics with one degree of freedom, based on logistic regression analysis. When $\chi^{2}$ is $>3.84, \mathrm{p}<$ 0.05 . "Added oontribution" described the extent to which one variable contributes any diagnostic information after adjustment for the other variable. The model only includes the patients for whom both the electrocardiogram and serum myoglobin were available for analysis $(n=70)$.
ST elevation. ${ }^{9}$ Since the induction of a fibrinolytic state is associated with increased morbidity, additional testing would be useful in the early identification of patients with acute myocardial infarction.

In accordance with previous studies ${ }^{4-7}$ we found ST elevation to be the most sensitive electrocardiographic criterion. The proportion of patients presenting with ST elevation during myocardial infarction varies from $18 \%{ }^{12}$ to $81 \%^{4}$ (mean $61 \%$ ). In our series, ST elevation correctly identified $64 \%$ of patients with myocardial infarction ( $11 \%$ false positive rate) (table 2). But on the criterion of ST elevation $36 \%$ of patients would not have been eligible for thrombolytic treatment. In our series, only $6 \%$ of patients with myocardial infarction had a "normal" electrocardiogram. Eleven per cent of patients without myocardial infarction had ST elevation. We do not know why this was. But others reported that the probability of myocardial infarction was low in the presence of ST elevation when there was a past history of myocardial infarction. ${ }^{13}$ We could not corroborate this finding in our series.

Raised serum concentrations of total creatine kinase and its MB fraction, though very sensitive and specific, tend to occur later than ST segment changes during the course of myocardial infarction. Our data indirectly support this finding because we found a significant positive correlation between the duration of chest pain and the serum concentration of creatine kinase and its $M B$ isoenzyme. This relation disappeared when we analysed patients who had had chest pain for $<6 \mathrm{~h}$. Furthermore, both creatine kinase and the $\mathrm{MB}$ isoenzyme were independently associated with myocardial infarction in the total study population, but this relation was not apparent when patients with prolonged chest pain were excluded.

Several studies have compared creatine kinase and creatine kinase $\mathrm{MB}$ with myoglobin during the early phase of myocardial infarction. In general these studies have found that serum myoglobin has a higher diagnostic sensitivity than creatine kinase and its isoenzyme, ${ }^{814}$ though one study found no difference between the early rise of creatine kinase $\mathrm{MB}$ and myoglobin. ${ }^{15}$ Our data support the superiority of myoglobin as an early marker of myocardial infarction because we found that myoglobin was a strong independent predictor of myocardial infarction in patients with symptoms of short duration.

Serum concentrations of myoglobin above the normal range have been found as early as one hour after myocardial infarction, with peak activity in the range of 4-12 hours. ${ }^{16}$ In addition, it has been suggested that serum myoglobin mirrors the early course of myocardial necrosis; this was substantiated by the temporal relation between myoglobin release and electrocardiographic changes in infarction. ${ }^{17}$ The overall cumulative release of myoglobin also correlates well with infarct size. Despite these impressive characteristics, serum myoglobin has not been used extensively for routine analysis in myocardial infarction. The main reason has been the very long assay times 


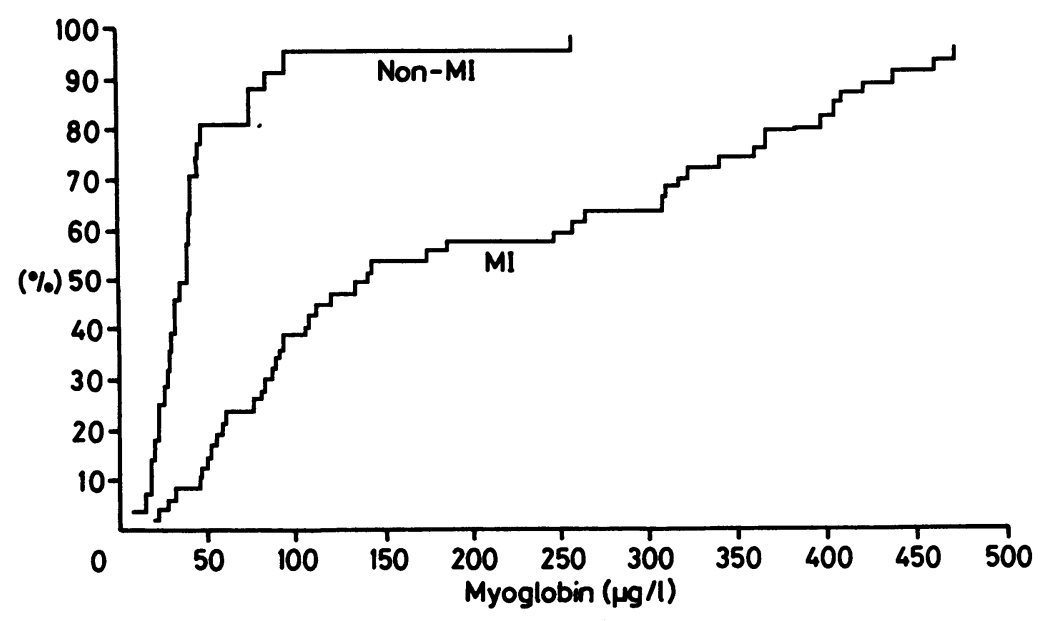

Figure 1 Cumulative distribution function describing the percentage of patients (ordinate) with and without a diagnosis of myocardial infarction for a given serum concentration of myoglobin (abscissa), as analysed by the radioimmunoassay. For example, the concentration was $<50 \mu \mathrm{g} / \mathrm{l}$ in $80 \%$ of those without myocardial infarction and in $13 \%$ of the patients with myocardial infarction. MI, myocardial infarction.

required, though more recent assays are becoming shorter. The rapid latex agglutination kit for myoglobin gives a result within ten minutes and can be performed by the bedside.

We found a good correlation between the serum concentration of myoglobin as measured by both the radioimmunoassay and the rapid latex agglutination kit. Other investigators have described similar findings, but noted a low reproducibility in the $80-140 \mu \mathrm{g} / 1$ range. ${ }^{18}$ The diagnostic information was greater with the serum test for myoglobin than with the kit method. The results of the radioimmunoassay showed that many patients with myocardial infarction had serum concentrations in the range of $50-90 \mu \mathrm{g} / \mathrm{l}$ (fig 1). Had $50 \mu \mathrm{g} / 1$ been used as the upper limit of normal, the sensitivity would have been $87 \%$ and the specificity $82 \%$ in this study population. This underscores the importance of establishing a normal range for the particular population under investigation so that suitable sensitivity and specificity can be developed.

The adjunctive value of serum concentrations of myoglobin to the electrocardiogram is clearly established in this study-the diagnostic accuracy of ST elevation was doubled. The electrocardiogram made only a small additional contribution to the diagnosis of myocardial infarction once the serum concentration of myoglobin was measured by radioimmunoassay. Similar findings were noted when the myoglobin kit was used. Valuable time would be lost if the radioimmunoassay was performed during myocardial infarction. The kit gives less diagnostic information than the

Figure 2 Algorithm for diagnosis of myocardial infarction in patients in whom both the electrocardiogram and serum myoglobin were available for analysis $(n=70)$. The algorithm is based on the assumption that additional testing is only necessary in patients without ST elevation. The calculated sensitivity was $82 \%$ and the specificity was $84 \%$. MI, myocardial infarction.

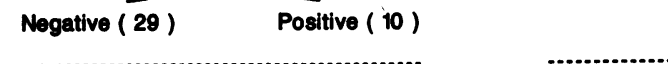

\begin{tabular}{|c|c|}
\hline $\begin{aligned} M & =8 \\
n o n-M & =21\end{aligned}$ & $\begin{array}{c}M=9 \\
n o n-M=1\end{array}$ \\
\hline
\end{tabular}

radioimmunoassay but it still enhances the diagnostic accuracy. In particular, $50 \%$ of patients with initially negative electrocardiograms and myocardial infarction were correctly diagnosed on the basis of their serum myoglobin concentrations, without an increase in the percentage of false positive results (fig 2). So a stepwise approach could be used and might improve the rapid identification of patients with myocardial infarction.

We examined potential markers of early myocardial infarction. In 82 consecutive patients ST elevation on the electrocardiogram and serum myoglobin were the variables that best identified myoeardial infarction. A short algorithm can be performed in ten minutes and gave an accurate diagnosis in $82 \%$ of patients. The hypothesis that rapid determination of serum myoglobin may improve the speed and accuracy of diagnosis in patients with suspected acute myocardial infarction deserves further evaluation.

This work was supported by the Edith Walsh award from the British Medical Association, London, and by a grant from the Royal College of Surgeons in Ireland. E M O was in receipt of a grant from the Medical Research Council of Ireland while this study was carried out.

1 Murray N, Lyons J, Layton C, Balcon R. What proportion of patients with myocardial infarction are suitable for thrombolysis? Br Heart J 1987;57:144-7.

2 Jagger JD, Murray RG, Davies MK, Littler WA, Fling EJ Eligibility for thrombolytic therapy in acute myocardial infarction. Lancet 1987;i:34-5.

3 Lee TH, Weisberg MC, Brand DA, Rouan GW, Goldman L. Candidates for thrombolysis among emergency room patients with acute chest pain. Ann Intern Med 1989; patients with

4 Rude RE, Poole WK, Muller JE, et al. Electrocardiographic and clinical criteria for recognition of acute myocardia infarction based on analysis of 3,697 patients. Am Cardiol 1983;52:936-42.

5 Blanke H, Cohen M, Schlueter GU, Karsch KR, Rentrop KP. Electrocardiographic and coronary arteriographic correlations during acute myocardial infarction. Am Cardiol 1984;54:249-55.

6 Yusuf S, Pearson M, Sterry H, et al. The entry ECG in the early diagnosis and prognostic stratification of patients with suspected acute myocardial infarction. Eur Heart $J$ 1984;5:690-6.

7 Bar FW, Vermeer F, De Zwaan C, et al. Value of admission electrocardiogram in predicting outcome of thrombolytic therapy. Am J Cardiol 1987;59:6-13.

8 Sylven C, Bendz R. Myoglobin, creatine kinase and its isoenzyme $\mathrm{MB}$ in serum after myocardial infarction. Eur $J$ isoenzyme MB in serum

9 ISIS-2 Collaborative Group. Randomized trial of intravenous streptokinase, oral aspirin, both, or neither among 17,187 cases of suspected acute myocardial infarction. Lancet 1988 ;ii:349-60.

10 Kubasik NP, Guiney W, Warren K, D'Souza JP, Sine HE, Brody BB. Radioimmunoassay of serum myoglobin evaluation and modification of a commercial kit and assessment of its usefulness of detecting acute myocardial infarction. Clin Chem 1978;24:2047-9.

11 Chapelle JP, Heusghem C. Semi-quantitative estimation of serum myoglobin by a rapid latex agglutination method: an emergency screening test for acute myocardial infarction. Clin Chim Acta 1985;145:143-50.

12 Short $D$. The earliest electrocardiographic evidence of myocardial infarction. Br Heart $J 1970 ; 32: 6-15$.

13 Miller DH, Kligfield P, Schreiber TL, Borer JS. Relationship of prior myocardial infarction to false-positive elecship of prior myocardial infarction to false-positive electrocardiographic diagnosis of acute injury in patie
chest pain. Arch Intern Med 1987;147:257-61.

14 Norregaard-Hansen $\mathrm{K}$, Lindo KE, Ludvigsen CV, Norgaard-Pedersen B. Serum myoglobin compared with gaard-Pedersen B. Serum myoglobin compared with creatine kinase in patients with acute m
tion. Acta Med Scand 1980;207:265-70.

15 Freeman AP, Fatches KR, Carter IW, Cloonan MJ, Wilcken DEL. Comparison of serum myoglobin and creatine kinase $\mathrm{MB}$ isoenzyme in early diagnosis of acute myocardial infarction. Br Heart J 1981;45:389-92.

16 Stone MJ, Willerson JT. Myoglobinemia in myocardial infarction. Int J Cardiol 1983;4:49-52.

17 Sederholm M, Sylven C. Relationship between ST and QRS vector changes and myoglobin release in acute myocardia infarction. Cardiovasc Res 1983;17:589-94.

18 Norregaard-Hansen K, Hangaard J, Norgaard-Pedersen B $A$ rapid latex agglutination test for detection of elevated levels of myoglobin in serum and its value in the early diagnosis of acute myocardial infarction. Scand J Clin Lab Invest 1984;44:99-103. 